Review Article

\title{
Nonpuerperal Uterine Inversion: What the Gynaecologists Need to Know?
}

\author{
R. P. Herath $\mathbb{D}^{1},{ }^{1}$ M. Patabendige ${ }^{D},{ }^{2}$ M. Rashid, ${ }^{3}$ and P. S. Wijesinghe ${ }^{1}$ \\ ${ }^{1}$ Department of Obstetrics and Gynaecology, Faculty of Medicine, University of Kelaniya, Kelaniya, Sri Lanka \\ ${ }^{2}$ University Obstetrics and Gynaecology Unit, Teaching Hospital, Mahamodara, Galle, Sri Lanka \\ ${ }^{3}$ Sidra Medicine, Doha, Qatar
}

Correspondence should be addressed to R. P. Herath; rasikaherath75@yahoo.com

Received 21 July 2019; Revised 24 March 2020; Accepted 13 May 2020; Published 1 June 2020

Academic Editor: W. T. Creasman

Copyright ( 92020 R. P. Herath et al. This is an open access article distributed under the Creative Commons Attribution License, which permits unrestricted use, distribution, and reproduction in any medium, provided the original work is properly cited.

Introduction. Nonpuerperal uterine inversion (NPUI) is a rare clinical problem with diagnostic and surgical challenges. The objective of our study was to review the literature on NPUI and describe causative pathologies, diagnosis, and different surgical options available for treatment. Materials and Methods. A comprehensive literature review was carried out on MEDLINE and Google Scholar databases to look for NPUI using the term "non-puerperal uterine inversion," and further went through the crossreferences of the published articles. Data are published case reports from 1911 to September 2018. Of the 153 published cases, 133 reports had adequate details of surgery for analysis. These reports were analyzed, concerning the clinical presentation, methods of diagnosis, and surgical treatment. Results. Mean age of the women was 46.3 years (standard deviation: 18, $N=153$ ). Leiomyoma remained the commonest (56.2\%) aetiology. While malignancies contributed to $32.02 \%$ of cases, $9.2 \%$ were idiopathic. High degree of clinical suspicion and identification of unique features on ultrasonography and magnetic resonance imaging enable prompt diagnosis. In cases of uncertainty, laparoscopy or biopsy of the mass was used to confirm the diagnosis. Hysterectomy or repositioning and repair of the uterus are the only treatment options available. The surgical methods implemented were analyzed in three aspects: route of surgical access, method of repositioning, and final surgical procedure undertaken. The majority (48.8\%) had only abdominal access, while $27.1 \%$ had both abdominal and vaginal access. Haultain procedure was the most useful procedure for reposition $(18.0 \%)$ of the uterus. The majority $(39.7 \%)$ required abdominal hysterectomy with or without debulking of the tumour abdominally, while $15.0 \%$ had uterine repair after repositioning. We reviewed the different surgical techniques and described and proposed a treatment algorithm. Conclusions. Fibroids were the commonest cause for NPUI. Malignancies accounted for one-third of cases. A combined abdominal and vaginal approach, followed by hysterectomy or repair after repositioning, seems to be better for nonmalignant cases.

\section{Introduction}

Uterine inversion is a condition where the fundus of the uterus turns inside out and the latter prolapses through the cervix. Puerperal uterine inversion was the first uterine inversion type to be recognized, possibly due to its common occurrence. In Ayurveda, the ancient Hindu system of medicine, there is some evidence to suggest that uterine inversion was known to them. However, Hippocrates (460-370 B.C.) is credited as the first to recognize uterine inversion $[1,2]$.
Inversion of the uterus was classified by Jones in 1951 into two types: puerperal or obstetric and nonpuerperal or gynaecological [3]. While puerperal inversions are seen following delivery or miscarriages and may be acute or chronic, the nonpuerperal variety is mostly related to benign or malignant tumours associated with the uterine corpus. Nonpuerperal inversions present mostly as chronic cases, although Das has reported $8.6 \%$ of nonpuerperal inversion as a sudden onset [1].

Nonpuerperal uterine inversion (NPUI) is rare, and actual incidence is not known. Most of the published 
literature on NPUI is in the form of case reports. We analyzed the possible causes and the treatment options used by the attending gynecologists in NPUI. To our knowledge, this is the first review to analyze the success rates of the treatment options used in cases of NPUI.

Even though the mechanism of obstetric uterine inversion is well understood, the mechanism of nonpuerperal inversion is not so clear. If the myometrium becomes distended due to a tumour within the cavity, it becomes irritable and initiates expulsive contractions, which can dilate the cervix and assists in the expulsion of the tumour, dragging its fundal attachment. The weight of the tumour, manual traction on the tumour, or increased intra-abdominal pressure due to coughing, straining, and sneezing may also contribute to NPUI $[1,2]$. With sarcomas, the area of the uterine wall weakened by the growth is believed to prolapse into the cavity and thus be brought under the influence of the active uterine musculature.

\section{Materials and Methods}

A comprehensive literature review found that, in 1911 and in 1940, Thorn et al. and Das et al. have reported 96 and 54 cases of NUPI, respectively $[1,4]$. We reviewed the literature from inception, published since the work of Thron et al. in 1911, till September 2018 in MEDLINE and Google Scholar databases using the term "non-puerperal uterine inversion" and further went through the cross-references of the published articles.

\section{Results}

Our literature search found 153 cases published since the publication of Das, accounting for 303 cases in total (Table 1). The mean age of the women was 46.3 years (SD-18) with a range of $14-88$ years.

3.1. Causes of NUPI. Leiomyoma was the commonest cause for NPUI found in our study accounting for $86(56.2 \%)$ of the case [5-86]. The nomenclature used by different authors to describe the causative pathology showed a big variation as the reported cases are published over many decades. We tried to group them into the following categories depending on available information. Carcinomas [87-99] and sarcomas $[3,24,100-109]$ accounted for 13 (8.5\%) each, while mixed Mullerian [106, 110-118] contributed to $10(6.5 \%)$ cases.

Rare causes such as fibrosarcoma [119], epidermoid carcinoma [120], endometrial sarcoma [121, 122], carcinosarcoma [123], rhabdomyosarcoma [124-127], endometrial polyp $[127,128]$, immature teratoma $[129,130]$, combination of fibroid and a cervical carcinoma [131], and pelvic organ prolapse $[132,133]$ contributed to $17(11.1 \%)$ cases of our study. There was no obvious cause for further 14 (9.2\%) cases [134-147] (Table 1). Turan et al. reported a case of cervical inversion without uterine inversion, which was not included in the study [148]. We noted that 49 out of 153 $(32.02 \%)$ cases were due to malignancies.

\section{Discussion}

4.1. Clinical Presentation and Diagnosis. Most women presented with foul-smelling vaginal discharge or irregular vaginal bleeding, some to the extent of causing anaemia needing blood transfusions [78]. There might be abdominal cramps, pelvic discomfort, and fullness of the vagina or pressure in the vagina. Chen et al. reported a case presenting as worsening dysmenorrhoea, menorrhagia, and dyspareunia. Acute urinary retention, needing suprapubic catheterization, has been described following NPUI [20]. Hypovolaemic shock has been reported in a case of acute uterine inversion due to a fibroid [16].

The inverted uterus forms an inverted pyriform swelling, which occupies the upper part of the vagina. In the case of total inversion, the mass will be protruding out of the introitus. It is smooth, dark red, and usually bleeds on palpation (Figure 1) [34]. If the tubal ostia is seen, it is conclusive of uterine inversion, but if the mass is infected or sloughing, ostia may not be easily seen [144].

Lascarides in 1968 described three important clinical signs in the diagnosis of NPUI: first, the cervical ring may not be recognizable along the proximal part of the mass; second, one cannot find the opening of uterine cervix or probe the endometrial cavity; third, rectal examination reveals that the uterus is not in its normal position in the pelvis, and the cupping of the fundus can sometimes be palpable [72]. It needs to be highlighted that the cervical ring is not identified only in cases of complete and total inversions. Furthermore, there are reported cases where the diagnosis of chronic NPUI was overlooked, and excision of the "vaginal mass" resulted in severing the fundus from the uterus and inadvertent entering into the peritoneal cavity [149].

NPUI has been classified into three groups depending on the degree of the inversion [12] (Table 2).

\subsection{Imaging}

4.2.1. Ultrasonography. Ultrasonography (USS) should be the first line of investigation considering availability and simplicity. USS can help with both the diagnosis of NPUI and diagnosis of its aetiology. Sonographic characteristics of "Y"-shaped uterine cavity, in the longitudinal plane are seen in incomplete uterine inversions. The base of " $\mathrm{Y}$ " is the noninverted endometrial lining. In contrast to incomplete inversion, the longitudinal view in complete inversion shows a " $U$ "-shaped configuration, with the limbs of the " $U$ " representing the complete inverted endometrial lining extending both anteriorly and posteriorly [42]. Some authors described the "target" sign while imaging the lower pelvis in the transverse plane, with the hyperechoic fundus surrounded by a rim, representing fluid within the space between the inverted fundus and the vaginal wall $[11,108]$.

During an ultrasound examination, leiomyomas usually appear as well-defined, solid, concentric, hypoechoic masses that cause a variable amount of acoustic shadowing [150]. However, the ultrasound observation of a large mass, with 
TABLe 1: Possible etiological factor of nonpuerperal uterine inversions.

\begin{tabular}{|c|c|c|c|c|c|c|c|}
\hline & Total number of cases & Leiomyoma & Sarcoma & Carcinoma & Mixed Mullerian tumour & Idiopathic & Others \\
\hline Thorn in 1911 [4] & 96 & $7(81 \%)$ & $1(1.04 \%)$ & $4(4.2 \%)$ & & $13(13.5 \%)$ & \\
\hline Das in 1940 [1] & 54 & $47(87.03 \%)$ & $3(5.5 \%)$ & $4(7.4 \%)$ & & & \\
\hline Our study $^{a}$ & 153 & $86(56.2 \%)$ & $13(8.5 \%)$ & $13(8.5 \%)$ & $5 \%)$ & $14(9.2 \%)$ & $17(11.1 \%)^{\mathrm{b}}$ \\
\hline Total reported cases & 303 & $210(69.5 \%)$ & $17(5.6 \%)$ & $21(6.9 \%)$ & $10(3.3 \%)$ & $27(8.9 \%)$ & $17(5.6 \%)$ \\
\hline
\end{tabular}

${ }^{\mathrm{a}}$ Cases from 1940 to $2018{ }^{\mathrm{b}} 13$ out of 17 cases were malignancies.

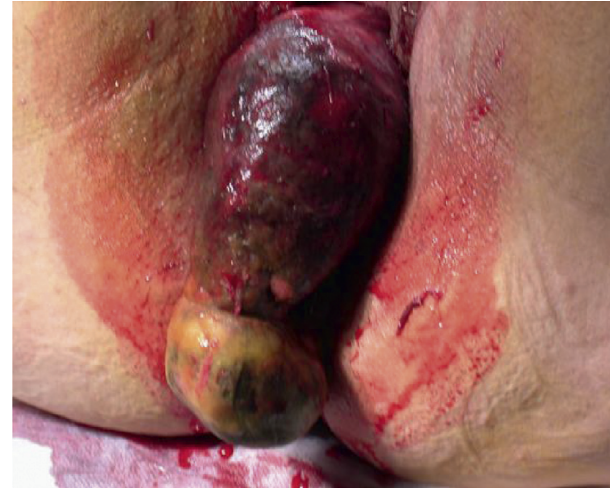

FIgURE 1: Macroscopic appearance of a complete nonpuerperal uterine inversion due to a fibroid [34].

inhomogeneous structure, without acoustic shadowing, and with rich central vascularization, assessed with colour Doppler has proven to be suspicious of malignancy [151]. On ultrasound, sarcomas typically appear as isolated large solid masses with inhomogeneous echogenicity of the solid tissue, sometimes containing cystic (usually irregular) areas and usually not having shadowing or calcifications [152, 153].

The 3D power Doppler with USS has been used more recently in the diagnosis of NPUI as it can clearly show the changes in the uterine artery course in relation to the uterine body. Zohov et al. emphasized that once the vaginal probe (with 3D power Doppler) is applied directly to the uterine corpus of inverted uterus, it showed bilateral uterine arteries in a longitudinal central location along the uterine body, with a U-turn sign, showing a central course of the main uterine vessels instead of their normal anatomical peripheral location laterally alongside the corpus of the uterus [81]. Ultrasonography has its limitations, the main being its operator dependency. In cases of NPUI, many reports of overlooking the diagnosis have been reported in the literature $[33,53,80]$. Despite above, Atalay et al. have emphasized the limited diagnostic value of transvaginal ultrasonography, in cases with large masses protruding into the vagina [33].

4.2.2. Magnetic Resonance Imaging (MRI). MRI is found to be sensitive in the diagnosis of NPUI. The distinct observations identified are U-shaped uterine cavity, a thickened and inverted uterine fundus on a sagittal section, and a "bull's eye" configuration on the horizontal section [93, 142]. U-shaped cavity could also be noted even in cases of inversion due to pedunculated tumours [93]. In complete inversion, identifying the round ligaments and fallopian tubes protruding centrally from the top of the uterus will help in arriving at the diagnosis (Figure 2) $[74,93,95,142]$. In case of a malignancy causing NPUI, MRI will further help in imaging lymph nodes.

4.2.3. CT Scan. CT scan has not been very useful in the diagnosis of NPUI. Especially in postmenopausal patients, inversion can be misdiagnosed as a cervical malignancy. But nonvisualization of the uterus and visualization of a lowdensity material in the middle of the pelvis due to oedematous endometrium and myometrium are features suggestive of uterine inversion. It can be an option in situations where MRI is not possible. The contrast-enhanced examination is favored for delineation [37].

4.3. Examination under Anaesthesia, Laparoscopy, Frozen Section, and Biopsy. In most of the case reports we reviewed, the difficulties of clinical diagnosis and interpretation of ultrasonography have been emphasized [53]. To overcome this, examining under anaesthesia and histological sampling of the vaginal mass have been suggested [53]. Demonstrating the endometrium on the surface of the mass will be confirmatory of the diagnosis. In our analysis, we found that $32.02 \%$ of NPUI were associated with malignancies. Therefore, histological evaluation of the mass is justifiable, before the definitive surgery, unless the causative pathology of a fibroid is obvious.

Viewing the pelvis at laparoscopy or laparotomy is an alternative way to confirm NPUI if the imaging modalities fail to provide a reasonable diagnosis. The appearance of ovaries and tubes projecting out of the indented uterine fundus has been described as the "flower vase appearance" in cases of NPUI (Figure 3) [74].

4.4. Treatment of NPUI. Initial assessment and resuscitation would be the priority as some patients may be in septic or in haemorrhagic shock, followed by correction of anaemia, pain relief, and starting antibiotics. Once stabilized, all steps should be followed to confirm the diagnosis and to establish the possible aetiology. The type and approach of surgery should be individualized considering the age, desire for future fertility, aetiology, and the stage of the disease in case of malignancy. We propose the guide given in the algorithm in Figure 4 to investigate and plan treatment.

If any uncertainty of the diagnosis exists after imaging, it should be cleared with laparoscopy and biopsy before definitive surgery is performed. If the biopsy confirms a 
TABLE 2: Stages of uterine inversion.

Stage 1

Stage 2

Stage 3

Stage 4
Inversion of the uterus is intrauterine or incomplete. The fundus remains within the cavity.

A complete inversion of the uterine fundus through the fibromuscular ring of the cervix.

Total inversion, whereby the fundus protrude through the vulva

The vagina is also involved with complete inversion through the vulva along with the inverted uterus
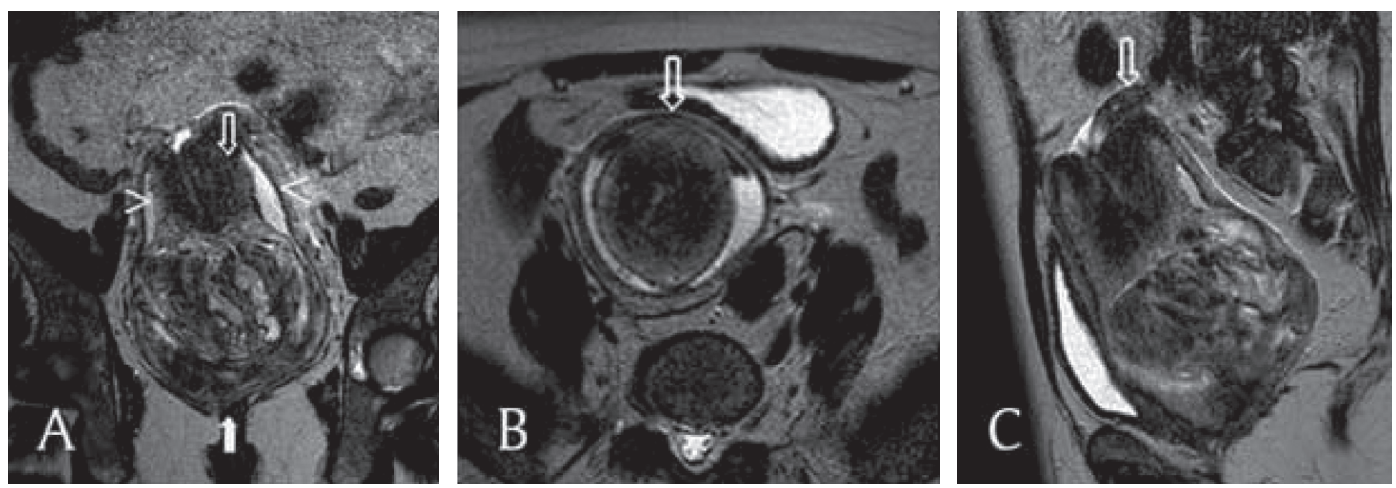

FIgURE 2: T2-weighted MRI of complete nonpuerperal uterine inversion due to fibroid. (a) This coronal image shows a vaginal heterogeneous mass (filled arrow), with the uterine corpus in a U-shape above the mass (empty arrow). The cervix surrounds the corpus, and the vaginal fornix surrounds both the corpus and the cervix (arrowheads). (b) This axial image shows, from the center outwards, the uterine corpus, the cervix, and the fornix and the invaginated round ligaments in a bullseye appearance (arrow). (c) This sagittal image shows one ovary above the cervix (arrow) [74].

malignancy, multidisciplinary involvement is important to plan the optimum treatment for the given type and stage of the malignancy.

Surgery is the mainstay of treatment of NPUI, focusing on the repositioning of the uterus. Repositioning is essential if uterine preservation is considered, as it is the only way to prevent pain, bleeding, infections, and gangrene. It should be assumed that hysterectomy would be technically easier on a normally positioned uterus, rather than the inverted uterus, as repositioning would restore normal anatomy with which gynecologists are familiar with.

While stage 1 inversion will often offer easy repositioning of the fundus, inversions of stages 2, 3, and 4 are likely to be more demanding. Exclusion of malignancy and excision of the causative benign tumour are essential before repositioning and repair. If repositioning is impossible, the only option left would be hysterectomy. Authors believe that attempting to reposition a uterus with a malignancy would be detrimental as the peritoneal cavity would be exposed to the pathology through the incised uterine wall.

Over many decades, authors have attempted different surgical options to solve NPUI, probably the first time they attended such a case. Only 133 out of 153 cases had details regarding the surgical management, and each of these 153 cases was analyzed for the suitability after careful reading by the authors. After analyzing these 133 cases where surgical details were available, we recognized three main aspects to consider: (1) route of surgical access (either abdominal, vaginal, or both), (2) attempt to reposition, and (3) planning of the eventual surgical procedure (resection of the causative tumour and repair or hysterectomy) as shown in Table 3.

When there is a mass protruding out of the vagina, it is tempting for the gynecologist to consider vaginal approach.
The vaginal approach was selected by $24(18.0 \%)$ surgeons, while $65(48.8 \%)$ surgeons have performed a laparotomy. The combined abdominal and vaginal approach was preferred by 36 (27.1\%) (Table 3). Most of the surgeons who opted for the latter have attempted the vaginal route first and subsequently went on to perform a laparotomy to complete the procedure. More recently, the laparoscopic approach has been used for diagnosis and as safety tools while performing vaginal hysterectomy [52]. The authors noted that most of the recent reports preferred either abdominal or combined approaches.

Techniques of repositioning uterus such as Huntington, Haultain, Spinelli, and Kustner's operations were initially described for treating puerperal inversions. Subsequently, surgeons have used the above procedures to treat NPUI also. Haultain procedure seems to be the most successful method to achieve repositioning $(18.0 \%, 24$ out of 133 cases) (Table 3$)$. In $52.3 \%$ cases, either the repositioning attempt failed or there was no mention of an attempt to reposition. Huntington procedure does not seem to be very successful in NPUI. Subtle variations of surgical techniques have been applied by surgeons to reposition the uterus. Table 3 summarizes the surgical methods used by previous authors to reposition the uterus and outcomes of the surgery.

A large proportion $(39.8 \%)$ of women underwent abdominal hysterectomy, while further $15.8 \%$ underwent vaginal debulking of the tumour followed by abdominal hysterectomy. An additional 19.6\% underwent a vaginal hysterectomy. After repositioning, $15.0 \%$ underwent uterine repair.

4.5. Abdominal Approaches. Huntington procedure involves laparotomy, locating the cup of uterus formed by the 


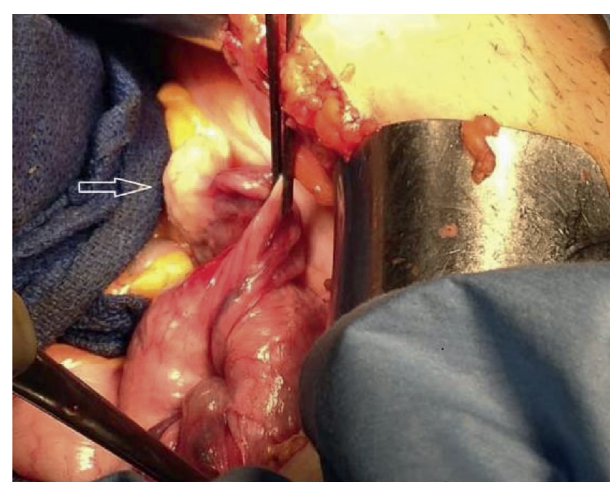

Figure 3: The appearance of ovaries and tubes projecting out of the indented uterine fundus has been described as the "flower vase appearance" in cases of nonpuerperal uterine inversion [74].

inversion, dilating the cervical ring digitally, and gentle upward traction of the round ligaments and the fundus of the uterus, to reposition the uterus. Nicol Haultain in 1908 described a procedure to replace puerperal uterine inversions. Following laparotomy, the inversion ring is incised posteriorly to facilitate repositioning with traction on the fundus [154]. Lai et al., in their case, repositioned the uterus during laparotomy by making an incision on the anterior aspect of the cervical constriction ring in contrast to Haultain procedure where the incision is made on the posterior ring [9].

Tjalma et al. described abdominal retroperitoneal dissection of ureters and uterine arteries, before progressing to hysterectomy after opening the vaginal wall anteriorly. They emphasized that identification of the ureter, in these cases where distorted anatomy is the hallmark, will minimize ureteric injuries [112]. Sharma et al. described abdominal resection of fibroid and abdominal hysterectomy. Round ligaments were clamped and cut followed by cornual fundal structures. After ligating the uterine arteries, the uterus was cut open with a midline vertical incision to remove the fibroid removed, and hysterectomy was completed as usual [26].

Skinner et al. reported a case of NPUI due to $6 \mathrm{~cm}$ atypical leiomyoma in a 27 -year-old woman who was committed to retaining fertility. The condition was confirmed at laparoscopy, and repositioning was attempted but failed. She was given three doses of gonadotrophin releasing hormone $(\mathrm{GnRH})$ analogue, over three months to shrink the fibroid. Three months later, the leiomyoma, which was $3 \mathrm{~cm}$ by now, was resected vaginally using an electrosurgical loop. Yet the uterus could not be repositioned and ended up in abdominal hysterectomy. Authors suggest that the pretreatment with the GnRH analogue made it difficult to reposition the uterus, thus increasing the resistance to dilate the cervix, although it made the fibroid smaller [12]. De Vries reported that they noted an accidental entry into the peritoneal cavity while trying to debulk the vaginal mass. Subsequently, they performed a laparotomy for safety and completion of the repair of the defect [29].

Krissi et al. performed a laparoscopy to confirm the diagnosis of NPUI before proceeding to vaginal myomectomy and subsequent laparotomy. $\mathrm{He}$ incised the constricting ring both anteriorly and posteriorly before repositioning the uterus [36]. Laparoscopic repositioning and repair were reported by Zhang et al. after releasing the anterior cervical ring during laparoscopy. They performed a vaginal myomectomy before repositioning [69].

4.6. Vaginal Approaches. In Kustner'ss operation, the pouch of Douglas is opened by posterior colpotomy, and the posterior uterine wall is incised. The surgeon's thumbs make pressure upon the rear wall of the uterus leading to reversion and restoring it to its normal position within the pelvis. The corpus is flipped through the posterior colpotomy, and the incision in the posterior uterine wall is repaired, having trimmed any myometrium if necessary, to achieve reapproximation of the serosal surface. The uterus is replaced within the pelvis, and the colpotomy is closed [15]. Alumi et al. noted that Kustner's procedure alone did not give enough space to reposition the uterus, and had to extend the incision along the posterior vaginal wall [146].

The Spinelli operation is similar in principle to the Kustner's operation, except that the incision into the uterine wall is made anteriorly after the bladder has been retracted upwards [14]. The uterus is then repositioned as in Kustner's operation. Once the repositioning has been done, uterine incision can be repaired or vaginal hysterectomy can be accomplished with the uterus in its anatomical position. Fofie and Baffoe reported a case with a slight modification to the Spinelli operation, where they had to extend the incision along the anterior uterine wall over the fundus to help reposition [30].

Mwinyoglee et al. reported an NPUI which was treated with vaginal hysterectomy without repositioning the uterus [106]. They used ultrasonography to locate the bladder in the cervico-forniceal region before making the incision. Once the bladder was safely dissected and pushed up, the uterosacral ligaments, cardinal ligaments, and the uterine arteries were dealt with in the standard manner. Then, they bisected the corpus to access the upper pedicles and completed the hysterectomy. They left the vaginal wall unclosed considering the gross edema.

Mayadeo and Tank, in 2003, described a case of incomplete lateral inversion of the uterus, diagnosed at laparoscopy, and treated with vaginal hysterectomy without repositioning the fundus [13]. In this case, as the inversion is incomplete, the lower pedicles could have been reached as in a routine vaginal hysterectomy. Herath et al. reported a case where they performed a vaginal hysterectomy under direct observation with a laparotomy [34]. Simms-Stewart et al. who treated a postmenopausal NPUI with subtotal vaginal hysterectomy did not attempt to remove the cervix considering the risks associated with the distorted anatomy [97]. The number of surgical modifications used in treating NPUI highlights the vast diversity of clinical presentations and surgical difficulties encountered by the gynaecologist. If the NPUI is due to a malignancy, treatment of the malignancy will take precedence.

4.7. Future Fertility. There are reports of successful pregnancies following the surgical correction of puerperal 


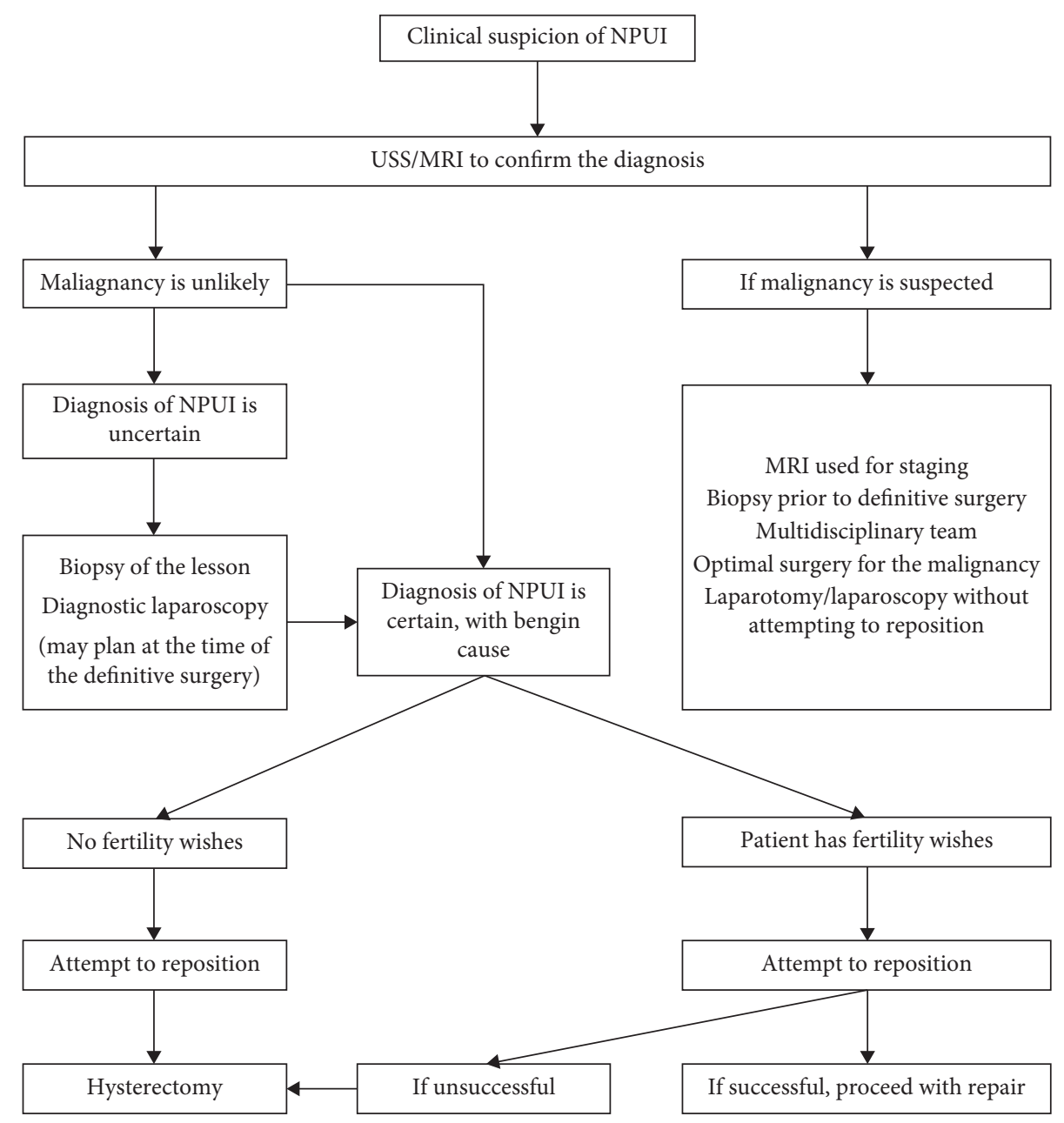

FIgURE 4: Treatment algorithm of nonpuerperal uterine inversion.

TABLE 3: Surgical options used in the treatment of NPUI.

Surgical detail

Number of cases

Approach to surgery

Abdominal

$N=133$

Vaginal

$65(48.8 \%)$

Combined abdominal and vaginal

$24(18 \%)$

$36(27.1 \%)$

Laparoscopy

Succeeded method of repositioning

$N=133$

Unsuccessful/not attempted

$69(51.9 \%)$

Haultain procedure

$24(18.0 \%)$

Spinelli procedure

$1(0.8 \%)$

Huntington procedure

$1(0.8 \%)$

Kustner's procedure

$8(6 \%)$

Bisecting the uterus

$2(1.5 \%)$

Repositioned after removing the mass without an additional procedure

$9(6.8 \%)$

Resection of the anterior cervical ring abdominally and repositioned

$5(3.8 \%)$

Others

$8(5.8 \%)$

No details

$6(4.5 \%)$

The final outcome of surgery

$N=133$

Total abdominal hysterectomy/subtotal hysterectomy (with or without abdominal debulking)

Vaginal debulking of the tumour/abdominal hysterectomy

Vaginal hysterectomy (with or without debulking)

Radical hysterectomy and pelvic node dissection

Repair after repositioning (either abdominal or vaginal) 
uterine inversion. Surprisingly, even though the literature repeatedly says to conserve the uterus if fertility is required, we could not find any evidence of successful pregnancy following repositioning of a nonpuerperal uterine inversion. Irani et al. reported a case where the uterus was repositioned with the Haultain procedure, yet the woman remained subfertile for two years after the operation [143].

Should uterine preservation be successful, there is no evidence to suggest the appropriate interval before attempting pregnancies following these techniques; however, in other recommendations of pregnancy interval following uterine surgery, greater than 12 months is suggested [155]. As with all uterine surgery, the risk of uterine rupture with subsequent delivery should be addressed.

\section{Conclusions}

Nonpuerperal uterine inversion is a rare clinical condition. Due to different presentations of the condition and the low incidence, it can be misdiagnosed on initial assessment. Leiomyomata are the commonest cause of uterine inversion, though a significant proportion was due to malignancies. USS and MRI have been used successfully in confirming the clinical diagnosis. The identification of endometrial tissue after biopsy or laparoscopy would be confirmatory if imaging could not differentiate the condition. Many surgical procedures have been described to treat NPUI, suggesting the diversity of clinical presentation and aetiology. The clinician, depending on the causative pathology, clinical presentation, desire for future fertility of the patient, and the surgical expertise, should select the best surgical approach. Haultain procedure seems to be the most successful method of repositioning the uterus, while the majority of women will require hysterectomy.

\section{Limitations}

The main limitation of the study is related to the rarity of the condition. The absence of clear diagnostic criteria or treatment approaches is evident, and the possible heterogeneity of the approaches reported in this review could be a limitation for the conclusions.

We could find full surgical details among 133 cases out of 153 published cases. Histopathological diagnosis among papers was not consistent, and with the available information, we could categorise only to the subheadings in Table 1 .

\section{Ethical Approval}

This article does not contain any studies with human participants or animals performed by any of the authors.

\section{Conflicts of Interest}

The authors report no conflicts of interest.

\section{Authors' Contributions}

RP Herath developed the project, collected data, analyzed data, and wrote and edited the manuscript. M Patabendige collected data, analyzed data, and wrote and edited the manuscript. M Rashid developed the project and edited the manuscript. PS Wijesinghe: edited the manuscript. All authors accepted the final version of the manuscript.

\section{References}

[1] P. Das, "Inversion of the uterus," BJOG: An International Journal of Obstetrics and Gynaecology, vol. 47, no. 5, pp. 525-548, 1940.

[2] V. Gowri, "Uterine inversion and corpus malignancies: a historical review," Obstetrical \& Gynecological Survey, vol. 55, no. 11, pp. 703-707, 2000.

[3] H. W. Jones, "Non-puerperal inversion of the uterus," The American Journal of Surgery, vol. 81, no. 5, pp. 492-495, 1951.

[4] W. Thorn, Zur inversio uteri, Gynaekologie, vol. 229, pp. 625-627, 1911.

[5] A. Culiner and G. P. Charlewwood, "The surgical management of chronic inversion on the uterus," South African Medical Journal, vol. 28, no. 22, pp. 459-460, 1954.

[6] M. R. Ellis, "A case of inversion of the uterus," British Medical Journal, vol. 2, no. 4889, pp. 686-687, 1954.

[7] J. M. Schulman and J. S. Stanton, "Acute nonpuerperal uterine inversion," Southern Medical Journal, vol. 74, no. 9, pp. 1142-1144, 1981.

[8] R. A. Krenning, P. J. Dörr, W. H. de Groot, and W. B. de Goey, "Non-puerperal uterine inversion: case report," British Journal of Obstetrics and Gynaecology, vol. 89, no. 3, pp. 247-249, 1982.

[9] F. M. Lai, P. Tseng, S. H. Yeo, and F. H. Tsakok, "Nonpuerperal uterine inversion-a case report," Singapore Medical Journal, vol. 34, no. 5, pp. 466-468, 1993.

[10] M. N. Barnes, K. R. Olvey, and M. G. Conner, "Nonpuerperal inversion of the uterus associated with endometrial stromal sarcoma," Journal of Gynecologic Surgery, vol. 16, no. 4, pp. 165-168, 2000.

[11] Şo Kopal, N. C. Seçkin, and N. Ö. Turhan, "Acute uterine inversion due to a growing submucous myoma in an elderly woman: case report," European Journal of Obstetrics \& Gynecology and Reproductive Biology, vol. 99, no. 1, pp. 118-120, 2001.

[12] G. N. Skinner and K. A. Louden, "Non-puerperal uterine inversion associated with an atypical leiomyoma," The Australian and New Zealand Journal of Obstetrics and Gynaecology, vol. 41, no. 1, pp. 100-101, 2001.

[13] N. M. Mayadeo and P. D. Tank, "Non-puerperal incomplete lateral uterine inversion with submucous leiomyoma: a case report," Journal of Obstetrics and Gynaecology Research, vol. 29, no. 4, pp. 243-245, 2003.

[14] L. Safdarian, L. Aleyassin, M. Forootan, and N. A. A. Kamalian, "Non-puerperal uterine inversion; a case report," Acta Medica Iranica, vol. 41, no. 1, pp. 59-61, 2003.

[15] E. Kioses, A. Pilalis, L. Hatzioannou, G. Moulopoulos, and A. Rodolakis, "Acute complete nonpuerperal uterine inversion," Acta Obstetricia et Gynecologica Scandinavica, vol. 83, no. 9, p. 870, 2004.

[16] T. Ashraf-Ganjooie, "Nonpuerperal uterine inversion: a case report," Archives of Iranian medicine, vol. 8, no. 1, pp. 63-66, 2005.

[17] J. H. Nelson and J. G. Sites, "Nonpuerperal inversion of the uterus," American Journal of Obstetrics and Gynecology, vol. 72, no. 3, pp. 660-662, 1956. 
[18] E. Rosales Aujang and R. González Romo, "Non-puerperal uterine inversion: report of a case," Ginecología y obstetricia de México, vol. 73, no. 6, pp. 328-331, 2005.

[19] P. V. Shivkumar, R. D. Barick, and C. Shambharkar, "Fundal leiomyoma presenting as acute on chronic uterine inversion," Journal of Obstetrics and Gynaecology, vol. 25, no. 8, pp. 832-833, 2005.

[20] Y.-L. Chen, C.-A. Chen, W.-F. Cheng et al., "Submucous myoma induces uterine inversion," Taiwanese Journal of Obstetrics and Gynecology, vol. 45, no. 2, pp. 159-161, 2006.

[21] U. Pandit, "Prolapsed uterine sarcoma causing non-puerperal uterine inversion in a post menopausal woman," Journal of Nepal Medical Association, vol. 45, no. 164, pp. 373-374, 2006.

[22] K. Rajab and A. I. A. Sandhu, "Chronic non puerperal inversion of uterus," Journal of the Bahrain Medical Society, vol. 18, pp. 202-220, 2006.

[23] S. Uludag, A. Gezer, and S. Erkan, "Posterior hemidissection for nonpuerperal uterine inversion," International Journal of Gynecology \& Obstetrics, vol. 93, no. 3, pp. 260-261, 2006.

[24] N. Eftekhari, "Non-peurperal uterine inversion in a virgin women," Iranian Journal of Reproductive Medicine, vol. 5, no. 3, pp. 135-136, 2007.

[25] J. O. Eigbefoh, S. A. Okogbenin, F. Omorogbe, and P. S. Mabayoje, "Chronic uterine inversion secondary to submucous fibroid: a case report," Nigerian Journal of Clinical Practice, vol. 12, no. 1, pp. 106-107, 2009.

[26] J. B. Sharma, S. Kumar, S. M. Rahman, K. K. Roy, and N. Malhotra, "Non-puerperal incomplete uterine inversion due to large sub-mucous fundal fibroid found at hysterectomy: a report of two cases," Archives of Gynecology and Obstetrics, vol. 279, no. 4, pp. 565-567, 2009.

[27] C. L Yi and S. Deshmukh, "Acute non puerperal uterine inversion," Bombay Hospital Journal, vol. 51, no. 4, pp. 490-491, 2009.

[28] D. P. Graham and R. D. Hill, "Inversion of nonpuerperal uterus: report of a case associated with fibromyomata uteri," Obstetrics and Gynecology, vol. 16, pp. 667-70, 1960.

[29] M. de Vries and D. A. M. Perquin, "Non-puerperal uterine inversion due to submucous myoma in a young woman: a case report," Journal of Medical Case Reports, vol. 4, no. 1, p. $21,2010$.

[30] C. O. Fofie and P. Baffoe, "Non-puerperal uterine invesion: a case report," Ghana Medical Journal, vol. 44, no. 2, pp. 79-81, 2011.

[31] C. C. Kilpatrick, L. Chohan, and R. C. Maier, "Chronic nonpuerperal uterine inversion and necrosis: a case report," Journal of Medical Case Reports, vol. 4, no. 1, p. 381, 2010.

[32] M. Auber, B. Darwish, A. Lefebure, J. Ness, and H. Roman, "Management of nonpuerperal uterine inversion using a combined laparoscopic and vaginal approach," The American Journal of Obstetrics and Gynecology, vol. 204, no. 6, pp. e7-e9, 2011.

[33] M. A. Atalay, B. Ç. Demir, N. Solak, F. O. Atalay, and S. Küçükkömürcü, "An unusual presentation of a submucous leiomyoma accounting to a non-puerperal uterine inversion: a case report," Journal of the Turkish-German Gynecological Association, vol. 14, no. 2, pp. 116-118, 2013.

[34] R. P. Herath, M. M. Hosni, M. Rashid, and M. Hassanaien, "Chronic nonpuerperal uterine inversion: laparotomy assisted vaginal hysterectomy case report chronic nonpuerperal uterine inversion: laparotomy assisted vaginal hysterectomy," American Journal of Obstetrics \& Gynecology, vol. 4, no. 2, pp. 7-10, 2011.
[35] H. Ishida, T. Yano, Y. Yasuda, A. Takashima, N. Takeshita, and T. Kinoshita, "Nonpuerperal uterine inversion due to submucous leiomyoma," Clinical Practice, vol. 1, no. 4, p. e105, 2011.

[36] H. Krissi, Y. Peled, Z. Efrat, and C. Goldshmit, "Ultrasound diagnosis and comprehensive surgical treatment of complete non-puerperal uterine inversion," Archives of Gynecology and Obstetrics, vol. 283, no. S1, pp. 111-114, 2011.

[37] O. M. Omololu, K. A. Rabiu, M. A. Quadri, M. O. Oyedeko, and Y. M. Fatogun, "Non puerperal uterine inversion due to submucous fibroid: a case report," The Nigerian Postgraduate Medical Journal, vol. 18, no. 2, pp. 158-160, 2011.

[38] R. Saxena, T. Shah, S. Thirumalappa, and K. Sarangapani, "Technique of abdominal hysterectomy for non-puerperal uterine inversion," Case Reports, vol. 2011, no. mar24 1, Article ID bcr0120113729, 2011.

[39] S. H. Riterband and S. P. Colquhoun, "Inversion of the uterus due to submucous fibroid," The Journal of Obstetrics and Gynaecology of the British Empire, vol. 66, pp. 961-963, 1959.

[40] F. F. Ymele, P. Nana, J. H. Fouedjio, E. Bechem, and R. E. Mbu, "Non-puerperal uterine inversion following a prolapsed leiomyoma in a cameroonianwoman," Clinics in Mother and Child Health, vol. 8, no. 1, pp. 1-3, 2011.

[41] P. Darji, H. Banker, V. Gandhi, and G. Thakkar, "Postmenopausal woman with vaginal mass: do not forget to see for uterine inversion," BMJ Case Reports, vol. 2012, no. aug09 1, Article ID bcr0220125841, 2012.

[42] C.-F. Hu and H. Lin, "Ultrasound diagnosis of complete uterine inversion in a nulliparous woman," Acta Obstetricia et Gynecologica Scandinavica, vol. 91, no. 3, pp. 379-381, 2012.

[43] Z. Muhammad and S. A. Y. I. Ibrahim, "Chronic non-puerperal uterine inversion: case series," Nigerian Journal of Basic and Clinical SciencesA, vol. 9, no. 2, pp. 87-90, 2012.

[44] A. Kumari, A. Vidhyarthi, and K. M. Salini, "Chronic uterine inversion secondary to submucous fibroid: a rare case report," International Journal of Scientific Study, vol. 3, no. 11, pp. 302-304, 2016.

[45] R. Tibrewal, S. Goswami, and P. S. Chakravorty, "Non puerperal uterine inversion," The Journal of Obstetrics and Gynecology of India, vol. 62, no. 4, pp. 452-453, 2012.

[46] T. Ashraf and S. Haroon, "Uterine inversion in postmenopausal woman: a rare entity," Journal of South Asian Federation of Menopause Societies, vol. 1, no. 2, pp. 88-90, 2013.

[47] J. Casanova, K.-G. Huang, A.-S. Adlan, and S. Artazcoz, "Uterine inversion caused by a submucous leiomyoma," Journal of Gynecologic Surgery, vol. 29, no. 6, pp. 294-296, 2013.

[48] C. Amorim-Costa and R. C. A. Mota, "Non-puerperal uterine inversion associated with a large submucoso volumoso," Acta Obstétrica e Ginecológica Portuguesa, vol. 7, pp. 70-72, 2013.

[49] N. Duhan, D. Sirohiwal, P. Bansal, and S. Choudhary, "Vaginal mass: myoma or uterine inversion or both?" European Journal of Obstetrics \& Gynecology and Reproductive Biology, vol. 170, no. 1, pp. 295-296, 2013.

[50] H. D. Webster, "Acute nonpuerperal inversion of the uterus. a case report," American Journal of Obstetrics and Gynecology, vol. 80, pp. 478-480, 1960.

[51] A. Pelissier-Komorek, M. Lucereau-Barbier, J. Diab, N. Gavillon, and O. Graesslin, "Acute non-puerperal uterine inversion the third degree," Gynécologie Obstétrique \& Fertilité, vol. 41, no. 2, pp. 130-132, 2013. 
[52] M. Shivanagappa, A. Bhandiwad, and M. Mahesh, "A case of acute on chronic uterine inversion with fibroid polyp," Journal of Clinical and Diagnostic Research, vol. 7, no. 11, pp. 2587-2588, 2013.

[53] O. S. Umeononihu, J. I. Adinma, N. J. Obiechina, G. U. Eleje, O. I. Udegbunam, and I. I. Mbachu, "Uterine leiomyoma associated non-puerperal uterine inversion misdiagnosed as advanced cervical cancer: a case report," International Journal of Surgery Case Reports, vol. 4, no. 11, pp. 1000-1003, 2013.

[54] T. Bakre, A. S. Gupta, and P. P. S. Hira, "Chronic non pueperal inversion of uterus secondary to submucosal fundal myoma," Journal of Postgraduate Gynecology \& Obstetrics, vol. 1, no. 10, 2014.

[55] B. Girija and T. Sudha, "Management of acute non-puerperal complete uterine inversion," Journal of Case Reports, vol. 4, no. 1, pp. 13-16, 2014.

[56] R. Katke, "Extremely rare case report of chronic inversion of uterus with submucous fundal fibroid with dragging of bladder wall and ureters along with: a case report and review of literature," International Journal of Reproduction, Contraception, Obstetrics and Gynecology, vol. 3, no. 2, pp. 479-482, 2014.

[57] M. Sarkar, D. Roy, J. Mondal, M. Halder, R. Ghosh, and B. K. Ghosh, "Non-puerperal acute uterine inversion," Nepal Journal of Obstetrics and Gynaecology, vol. 9, no. 1, pp. 58-60, 2014.

[58] S. Ghosh, S. K. Samal, P. Pallavee, and S. Ghose, "Non puerperal uterine inversion in a young female- a case report," Journal of Clinical and Diagnostic Research, vol. 8, no. 9, pp. OD01-OD02, 2014.

[59] S. Shabbir, M. Ghayasuddin, S. M. Younus, and K. Baloch, "Chronic non puerperal uterine inversion secondary to submucosal fibroid," Journal of Pakistan Medical Association, vol. 64, no. 5, pp. 586-588, 2014.

[60] G. S. Anitha, V. R. Manjulatha, and R. Ramaiah, "Nonpuerperal uterine inversion: a case report," International Journal of Reproduction, Contraception, Obstetrics and Gynecology, vol. 4, no. 4, pp. 1223-1226, 2015.

[61] A. Sitaratna and V. Sarma, "Fundal fibromyoma of the uterus causing nonpuerperal inversion," Adseptic, vol. 59, pp. 435-438, 1962.

[62] M. R. Datta, D. S. Nag, and M. Kabiraj, "Non-puerperal uterine inversion in a patient with intracranial sigmoid sinus thrombosis and facial palsy," BMJ Case Reports, vol. 2015, no. may12 1, Article ID bcr2014206937, 2015.

[63] G. Deka, G. Ch Das, and H. Gautam, "Non puerperal uterine inversion with fibroid polyp-a case report," New Indian Journal of $O B G Y N$, vol. 2, no. 2, 2015.

[64] A. Elghanmi, M. Jou, and A. Baydada, "Nonpuerperal uterine inversion," Journal of Gynecologic Surgery, vol. 31, no. 5, pp. 299-302, 2015.

[65] A. Kouamé, S. V. Koffi, R. Adjoby et al., "Non-puerperal uterine inversion in a young woman: a case report," Journal of The West African College of Surgeons, vol. 5, no. 3, pp. 78-83, 2015.

[66] V. Mihmanli, F. Kilic, S. Pul, A. Kilinc, and A. Kilickaya, "Magnetic resonance imaging of non-puerperal complete uterine inversion," Iranian Journal of Radiology, vol. 12, no. 4, p. e9878, 2015.

[67] A. S. El-Agwany and E.-S. El-Badawy, "Non puerperal total uterine inversion with cervical and vaginal inversion: an unusual complication of degenerated submucous fundal fibroid treated by vaginal hysterectomy," The Egyptian
Journal of Radiology and Nuclear Medicine, vol. 46, no. 4, pp. 1323-1326, 2015.

[68] M. Sakıncı, C. Y. Sanhal, G. İnayet Çelik, Ş Olgan, and N. U. Doğan, "Uterine inversion as an extremely rare cause of secondary infertility: a case report," Turkish Journal of Obstetrics and Gynecology, vol. 12, no. 1, pp. 50-52, 2015.

[69] X. Zhang, L. Sun, X. Chen, and K. Hua, “Uterus preserving reposition of non-puerperal uterine inversion under laparoscope: a case report and literature review," Gynecologic and Obstetric Investigation, vol. 79, no. 3, pp. 206-209, 2015.

[70] D. Asefa and N. Yimar, "Chronic postmenopausal uterine Inversion : a case report gynecology \& obstetrics," Gynecol Obstetrics, vol. 6, no. 6, 2016.

[71] A. O. Durodola, A. O. Fehintola, O. T. Awotunde, C. A. Attansey, O. I. Aaron, and G. H. Ano-Edward, "Nonpuerperal acute uterine inversion in a nullipara," Journal of Gynecologic Surgery, vol. 32, no. 3, pp. 185-8, 2016.

[72] E. Lascarides and M. Cohen, "Surgical management of nonpuerperal inversion of the uterus," Obstetrics \& Gynecology, vol. 32, no. 3, pp. 376-381, 1968.

[73] H. Gehlot, P. Choudhary, and S. Sharma, "Chronic nonpuerperal uterine inversion: a rare case report," International Journal of Reproduction, Contraception, Obstetrics and Gynecology, vol. 5, no. 5, pp. 1629-1632, 2016.

[74] I. Leconte, C. Thierry, A. Bongiorno, M. Luyckx, and L. Fellah, "Non-puerperal uterine inversion," Journal of the Belgian Society of Radiology, vol. 100, no. 1, p. 47, 2016.

[75] E. Kalarani, A. Amudha, M. Rubini, and A. Karthika, "Nonpuerperal inversion of uterus secondary to leiomyoma in menopause: a rare case report," International Journal of Reproduction, Contraception, Obstetrics and Gynecology, vol. 5, no. 8, pp. 2859-2861, 2016.

[76] L. F. Pinder, K. O. Ouma, and B. D. Nelson, "Non-puerperal uterine inversion in a young woman: a case report, brief surgical review, and clinical insights," Clinical Medical Reviews and Case Reports, vol. 3, no. 8, p. 122, 2016.

[77] S. Soysal, G. A. İlhan, M. Vural, B. Yildizhan, and T. Pekİn, "Non-puerperal uterin inversion caused by myoma of the uterus," Gynecology Obstetrics \& Reproductive Medicine, vol. 22, pp. 40-41, 2016.

[78] Y. J. Song, J. Yang, H. S. Yun et al., "Non-puerperal uterine inversion presented with hypovolemic shock," Journal of Menopausal Medicine, vol. 22, no. 3, pp. 184-187, 2016.

[79] S. Chawla, G. C. Gupta, and S. Lakhanpal Kalia, "Chronic non-puerperal inversion of the uterus; a rare entity," Global journal for research analysis, vol. 6, no. 11, pp. 346-347, 2017.

[80] B. Teimoori and A. Esmailzadeh, "A large uterine leiomyoma leading to non-puerperal uterine inversion: a case report," International Journal of Reproductive Biomedicine (Yazd, Iran), vol. 15, no. 1, pp. 55-6, 2017.

[81] E. Zohav, E. Y. Anteby, and L. Grin, "U-turn of uterine arteries: a novel sign pathognomonic of uterine inversion," Journal of Ultrasound, vol. 23, no. 1, pp. 77-79, 2018.

[82] T. Lima, R. Sousa, A. Pinheiro, and A. Almeida, "Chronic non-puerperal uterine inversion in an asymptomatic woman," Journal of Obstetrics and Gynaecology, vol. 38, no. 6, pp. 880-881, 2018.

[83] G. L. Pride and R. L. Shaffer, "Nonpuerperal uterine inversion. report of an unusual case," Obstetrics and Gynecology, vol. 49, no. 3, pp. 361-364, 1977.

[84] L. Della Corte, P. Giampaolino, A. Fabozzi, A. Di Spiezio Sardo, and G. Bifulco, "An exceptional uterine inversion in a virgo patient affected by submucosal leiomyoma: case report 
and review of the literature," Journal of Obstetrics and Gynaecology Research, vol. 45, no. 2, pp. 466-472, 2018.

[85] N. H. Al Qahtani, "Chronic incomplete non-puerperal uterine inversion due to huge submucous fibroid: diagnosis and management," BMJ Case Reports, vol. 2018, 2018.

[86] P. R. Henderson, "A large submucous fibroid polyp causing inversion of the uterus," Australian and New Zealand Journal of Obstetrics and Gynaecology, vol. 20, no. 4, pp. 251-254, 1980.

[87] J. K. Craig, "Inversion of the uterus associated with a malignant tumour in a girl of 14 years of age," BJOG: An International Journal of Obstetrics and Gynaecology, vol. 65, no. 3, pp. 497-499, 1958.

[88] A. O. Karjalaien, "Inversion of the uterus with coincidental uterine carcinoma," Annales Chirurgiae et Gynaecologiae Fenniae, vol. 54, pp. 174-180, 1965.

[89] M. Préfontaine, "Complete uterine inversion in a patient with endometrial cancer," Journal of Obstetrics and Gynaecology Canada, vol. 34, no. 7, p. 609, 2012.

[90] S. M. Sims, L. Cooper, and S. D. J. Byun, "Uterine sarcoma presenting in the setting of non-puerperal uterine inversion with uterine prolapse," Journal of Genital System \& Disorders, vol. 1, no. 1, p. 1, 2012.

[91] N. Fasih and Y. Sardar, "Non-puerperal uterine inversion associated with a pelvic mass," Journal of Cancer Allied Specialities, vol. 1, no. 1, p. 12, 2015.

[92] M. L. Tancer, H. Brockway, and C. Solomon, "Chronic nonpuerperal inversion of uterus associated with undifferentiated carcinoma," New York state journal of medicine, vol. 65 , no. 22, pp. 2824-2826, 1965.

[93] F. Moulding and J. M. Hawnaur, "MRI of non-puerperal uterine inversion due to endometrial carcinoma," Clinical Radiology, vol. 59, no. 6, pp. 534-537, 2004.

[94] G. Kumar and K. Reynolds, "Uterine inversion associated with endometrial carcinoma: a case report," Journal of Obstetrics and Gynaecology, vol. 25, no. 1, pp. 91-92, 2005.

[95] H. Oguri, N. Maeda, Y. Yamamoto, A. Wakatsuki, and T. Fukaya, "Non-puerperal uterine inversion associated with endometrial carcinoma-a case report," Gynecologic Oncology, vol. 97, no. 3, pp. 973-975, 2005.

[96] K. Ueda, A. Okamoto, K. Yamada et al., "Nonpuerperal inversion of the uterus associated with endometrial cancer: $\mathrm{a}$ case report," International Journal of Clinical Oncology, vol. 11, pp. 153-155, 2006.

[97] D. Simms-Stewart, S. Frederick, H. Fletcher, G. Char, and S. Mitchell, "Postmenopausal uterine inversion treated by subtotal hysterectomy," Journal of Obstetrics and Gynaecology, vol. 28, pp. 116-117, 2008.

[98] E. Korshid and I. A. Al-Badawi, "Uterine sarcoma: a rare cause of uterine inversion," Hematology/Oncology and Stem Cell Therapy, vol. 4, no. 3, pp. 144-146, 2011.

[99] R. Sachan and P. P. M. Gupta, "Uterine leiomyosarcoma presenting as chronic inversion of uterus- a rare case report," International Journal of Medical and Medicine Sciences, vol. 4, no. 3, pp. 49-51, 2012.

[100] S. Buyukkurt, M. A. Vardar, H. Zeren, and F. T. Ozgunen, "Non-puerperal inversion of the uterus caused by leiomyosarcoma: a case report and clinical management," Journal of Obstetrics and Gynaecology Research, vol. 33, no. 3, pp. 402-406, 2007.

[101] J. Mechery, E. J. Crosbie, S. Desai, H. Mamtora, and R. J. Slade, "Uterine sarcoma: a rare cause of uterine inversion," Journal of Obstetrics and Gynaecology, vol. 29, no. 8, pp. 776-778, 2009.
[102] C. V. Salisbury, W. Newman, and G. Scarf, "Chronic nonpuerperal inversion of the uterus," Medical Journal of Australia, vol. 45, no. 17, pp. 565-566, 1958.

[103] E. Holzer, "Uterus inversion due to tumor: case report," Gynakologische Rundschau, vol. 19, no. 3, pp. 150-155, 1979.

[104] N. S. Louw and J. van Schouwenburg, "Inversion of the uterus in a 14-year-old Xhosa girl; case report," South African Medical Journal (SAMJ), vol. 57, no. 11, pp. 421-422, 1980.

[105] F. Bensaid, S. El Hajoui, S. Nabil et al., "Nonpuerperal uterine inversion revealing the presence of a uterine sarcoma: case report and review of the literature," Congrès Colloq avec le Prat-Entret Bichat, vol. 91, no. 10, pp. 493-495, 1996.

[106] J. Mwinyoglee, N. Simelela, and M. Marivate, "Non-puerperal uterine inversions: a two case report and review of literature," Central African Journal of Medicine, vol. 43, no. 9, pp. 268-271, 1997.

[107] C. A. Rattray, C. N. Parris, G. Chisholm, and K. C. Coard, "Complete non-puerperial uterine inversion as a result of a uterine sarcoma," West Indian Medical Journal, vol. 49, no. 3, pp. 245-247, 2000.

[108] K. Takano, Y. Ichikawa, H. Tsunoda, and M. Nishida, "Uterine inversion caused by uterine sarcoma: a case report," Japanese Journal of Clinical Oncology, vol. 31, no. 1, pp. 39-42, 2001.

[109] A. Lupovitch, E. R. England, and R. Chen, "Non-puerperal uterine inversion in association with uterine sarcoma: case report in a 26-year-old and review of the literature," Gynecologic Oncology, vol. 97, no. 3, pp. 938-941, 2005.

[110] B. Zorn, Y. Chitrit, E. Constancis, C. Chleq, L. Vergnes, and J. Milliez, "Malignant mixed mesodermal tumor detected by uterine inversion: apropos of a case. review of the literature," Revue française de gynécologie et d'obstétrique, vol. 85, no. 3, pp. 186-193, 1990.

[111] M. Moodley and J. Moodley, "Non-puerperal uterine inversion in association with uterine sarcoma: clinical management," International Journal of Gynecological Cancer, vol. 13, no. 2, pp. 244-245, 2003.

[112] W. A. A. Tjalma, R. Naik, J. M. Monaghan, and A. De Barros Lopes, "Uterine inversion by a mixed müllerian tumor of the corpus," International Journal of Gynecological Cancer, vol. 13, no. 6, pp. 894-897, 2003.

[113] J. Hanprasertpong, V. Wootipoom, and T. Hanprasertpong, "Non-puerperal uterine inversion and uterine sarcoma (malignant mixed müllerian tumor): report of an unusual case," Journal of Obstetrics and Gynaecology Research, vol. 30, no. 2, pp. 105-108, 2004.

[114] G. Cormio, V. Loizzi, C. Nardelli, N. Fattizzi, and L. Selvaggi, "Non-puerperal uterine inversion due to uterine sarcoma," Gynecologic and Obstetric Investigation, vol. 61, no. 3, pp. 171-173, 2006.

[115] O. Gemer, E. Anteby, and O. Lavie, "Uterine inversion associated with uterine sarcoma," International Journal of Gynecology \& Obstetrics, vol. 101, no. 2, pp. 195-196, 2008.

[116] M. Occhionero, G. Restaino, M. Ciuffreda, A. Carbone, G. Sallustio, and G. Ferrandina, "Uterine inversion in association with uterine sarcoma: a case report with MRI findings and review of the literature," Gynecologic and $\mathrm{Ob}$ stetric Investigation, vol. 73, no. 3, pp. 260-264, 2012.

[117] R. Mehra, S. Siwatch, S. Arora, and R. Kundu, "Non-puerperal uterine inversion caused by malignant mixed mullerian sarcoma," BMJ Case Reports, vol. 2013, no. dec12 1, Article ID bcr2013200578, 2013. 
[118] J. A. Attapattu, "Inversion of the uterus associated with a mesodermal mixed tumour in a young female," Ceylon Medical Journal, vol. 20, no. 4, pp. 241-246, 1975.

[119] W. J. Reich and M. J. Nechtow, "Chronic inversion of the uterus with fibrosarcoma of the corpus," American Journal of Surgery, vol. 71, pp. 710-712, 1946.

[120] C. F. Gillespie, "Chronic inversion of the uterus with presenting epidermoid carcinoma: report of a case," Obstetrics \& Gynecology, vol. 20, pp. 801-804, 1962.

[121] F. V. Lana, "Endometrial sarcoma and total uterine inversion," Journal of Medicinal (Oporto), vol. 49, pp. 175-178, 1962.

[122] C. E. Ehrlich and L. M. Bonaventura, "Nonpuerperal inversion of the uterus by endometrial stromal sarcoma of the uterine fundus," Southern Medical Journal, vol. 70, no. 7, pp. 872-873, 1977.

[123] G. A. P. Bernardini, "Carcinosarcoma and total inversion of the uterus. (presentation of a case)," Quaderni di Clinica Ostetrica e Ginecologica, vol. 18, no. suppl 1, p. 1500, 1963.

[124] A. S. Case, T. O. Kirby, M. G. Conner, and W. K. Huh, "A case report of rhabdomyosarcoma of the uterus associated with uterine inversion," Gynecologic Oncology, vol. 96, no. 3, pp. 850-853, 2005.

[125] A. Sharma, S. Rajaram, N. Goel, U. R. Singh, S. Ghumman, and H. Sharma, "Uterine rhabdomyosarcoma presenting as acute inversion in an adolescent," Australian and New Zealand Journal of Obstetrics and Gynaecology, vol. 46, no. 1, pp. 60-61, 2006.

[126] S. B. O. Ojwang, F. Rana, S. Sayed, and W. K. Aruasa, "Embryonal rhabdomyosarcoma with uterine inversion: case report," East African Medical Journal, vol. 83, no. 3, pp. 110-113, 2006.

[127] B. B. da Silva, A. R. dos Santos, J. Bosco Parentes-Vieira, P. V. Lopes-Costa, and C. G. Pires, "Embryonal rhabdomyosarcoma of the uterus associated with uterine inversion in an adolescent: a case report and published work review," Journal of Obstetrics and Gynaecology Research, vol. 34, no. 4pt2, pp. 735-738, 2008.

[128] R. Rocconi, W. K. Huh, and S. Chiang, "Postmenopausal uterine inversion associated with endometrial polyps," $\mathrm{Ob}$ stetrics and Gynecology, vol. 102, no. 3, pp. 521-523, 2003.

[129] V. Gomez-Lobo, W. Burch, and P. C. Khanna, "Nonpuerperal uterine inversion associated with an immature teratoma of the uterus in an adolescent," Obstetrics and Gynecology, vol. 112, no. 3, pp. 708-709, 2008.

[130] K. T. Souza, M. V. Negrão, L. S. da Silva Rocha, G. Di Favero, S. C. S. da Costa, and M. D. P. E. Diz, "Immature uterine teratoma associated with uterine inversion," Rare Tumors, vol. 6, no. 3, pp. 111-113, 2014.

[131] K. Dahiya, R. H. More, H. More, and A. Dahiya, "Nonpuerperal uterine inversion caused by fibroid polyp associated with squamous-cell carcinoma of the cervix," Journal of Gynecologic Surgery, vol. 25, no. 1, pp. 37-40, 2009.

[132] C. Reisenauer and E. Solomayer, "Pelvic-organ prolapse and uterine inversion," New England Journal of Medicine, vol. 360, no. 12, p. 1238, 2009.

[133] A. Naidu, Z. Nusee, and S. Tayib, "Uterine inversion with massive uterovaginal prolapse and multiple bladder stones," Journal of Obstetrics and Gynaecology Research, vol. 37, no. 6, pp. 633-635, 2011.

[134] E. Selkin-Aronson and B. Karen, "Nonpuerperal inversion of the uterus," American Journal of Obstetrics and Gynecology, vol. 42, no. 3, pp. 540-542, 1941.

[135] H. Acosta-Sison, "Acute complete inversion of the uterus with a large uterine polyp after an enema," Philippine Journal of Surgery, vol. 6, no. 1, pp. 27-29, 1951.
[136] S. Rudra, N. Naredi, B. Duggal, and A. Seth, "Chronic uterine inversion: a rare complication of mismanaged labour," Medical Journal Armed Forces India, vol. 66, no. 1, pp. 91-92, 2010.

[137] S. Coumary and G. Seetesh, "Complete chronic uterine inversion with eventration of the vagina," Taiwanese Journal of Obstetrics and Gynecology, vol. 53, no. 1, pp. 107-108, 2014.

[138] O. Birge and A. Merdin, "Chronic total uterine inversion in an adolescent," Clinical Case Reports, vol. 3, no. 11, pp. 966-967, 2015.

[139] E. Ali and M. Kumar, "Chronic uterine inversion presenting as a painless vaginal mass at 6 months post partum: a case report," Journal of Clinical and Diagnostic Research, vol. 10, no. 5, pp. QD07-QD08, 2016.

[140] K. K. Kulkarni and S. K. Ajmera, "A rare case of non-puerperal acute uterine inversion," The Journal of Obstetrics and Gynecology of India, vol. 64, no. 5, pp. 364-365, 2014.

[141] C. J. Mackinlay, "A case of chronic inversion of the uterus," BJOG: An International Journal of Obstetrics and Gynaecology, vol. 65, no. 5, pp. 810-816, 1958.

[142] C. G. Salomon and S. K. Patel, "Computed tomography of chronic nonpuerperal uterine inversion," Journal of Computer Assisted Tomography, vol. 14, no. 6, pp. 1024-1026, 1990.

[143] S. Irani, K. Jeyapalan, J. McHugo, and J. A. Jordan, "Chronic non-puerperal inversion of the uterus," Journal of Obstetrics and Gynaecology, vol. 18, no. 2, pp. 202-203, 1998.

[144] S. E. Adaji, A. J. Randawa, and O. S. Shittu, "Idiopathic chronic uterine inversion in a nulligravida," International Journal of Gynecology \& Obstetrics, vol. 89, no. 1, pp. 61-62, 2005.

[145] S. L. Livingston, C. Booker, P. Kramer, and W. C. Dodson, "Chronic uterine inversion at 14 weeks postpartum," $\mathrm{Ob}$ stetrics and Gynecology, vol. 109, no. 2 Pt2, pp. 555-557, 2007.

[146] N. Alumi, A. Deyhar, D. Gahn, and G. Davis, "Nonpuerperal uterine inversion in an afghan woman," Military Medicine, vol. 174, no. 5, pp. 542-543, 2009.

[147] N. S. Sardeshpande, R. M. Sawant, S. N. Sardeshpande, and S. D. Sabnis, "Laparoscopic correction of chronic uterine inversion," Journal of Minimally Invasive Gynecology, vol. 16, no. 5, pp. 646-648, 2009.

[148] N. Turhan, S. Simavli, I. Kaygusuz, and B. Kasap, "Totally inverted cervix due to a huge prolapsed cervical myoma simulating chronic non-puerperal uterine inversion," International Journal of Surgery Case Reports, vol. 5, no. 8, pp. 513-515, 2014.

[149] R. A. Krenning, "Nonpuerperal uterine inversion: review of literature," Clinical and Experimental Obstetrics \& Gynecology, vol. 9, no. 1, pp. 12-15, 1982.

[150] A. Woźniak and S. Woźniak, "Ultrasonography of uterine leiomyomas," Przeglad Menopauzalny= Menopause Review, vol. 16, no. 4, pp. 113-117, 2017.

[151] C. Frascà, G. Tuzzato, A. Arena et al., "The role of pelvic ultrasound in preoperative evaluation for laparoscopic myomectomy," Journal of Minimally Invasive Gynecology, vol. 25, no. 4, pp. 679-683, 2018.

[152] M. Ludovisi, F. Moro, T. Pasciuto et al., "Imaging in gynecological disease (15): clinical and ultrasound characteristics of uterine sarcoma," Ultrasound in Obstetrics \& Gynecology, vol. 54, no. 5, pp. 676-687, 2019.

[153] J. Y. Verbakel, F. Mascilini, L. Wynants et al., "Validation of ultrasound strategies to assess tumor extension and to predict high-risk endometrial cancer in women from the 
prospective ieta (international endometrial tumor analysis)4 cohort," Ultrasound in Obstetrics \& Gynecology, vol. 55, no. 1, pp. 115-124, 2020.

[154] F. W. Haultain, "Abdominal hysterotomy for chronic uterine inversion: a record of three cases," Proceedings of the Royal Society of Medicine, vol. 1, no. Obstet Gynaecol Sect, pp. 279-290, 1908.

[155] Y. Zhang and K. Q. Hua, "Patients' age, myoma size, myoma location, and interval between myomectomy and pregnancy may influence the pregnancy rate and live birth rate after myomectomy," Journal of Laparoendoscopic \& Advanced Surgical Techniques, vol. 24, no. 2, pp. 95-99, 2014. 